\title{
A modernidade nos clássicos da Sociologia: percepções acerca do mundo moderno em Tocqueville, Durkheim e Weber
}

\author{
Renan Oliveira de Carvalho'
}

Recebido em maio de 2019 Aceito em outubro de 2019

\begin{abstract}
RESUMO
O presente artigo procura trazer reflexões acerca das concepções sobre a modernidade em três dos maiores clássicos da sociologia, Émile Durkheim, Max Weber e Alexis de Tocqueville. A proposta é fornecer uma visão introdutória sobre a abordagem sociológica e os diagnósticos que esses autores ofereceram acerca da experiência moderna. Para isso, busco introduzir o leitor à discussão a partir do pensamento do historiador Reinhart Koseleck sobre a temporalidade moderna, para a partir desta lente tentar lançar luz às concepções acerca do mundo moderno nos três autores clássicos mencionados.
\end{abstract}

Palavras-chave: Modernidade; Weber; Durkheim; Tocqueville.

\section{ABSTRACT}

The present article seeks to bring reflections on the conceptions of modernity in three of the greatest classics of sociology, Émile Durkheim, Max Weber and Alexis de Tocqueville. The proposal is to provide an introductory insight into the sociological approach and diagnoses these authors offers about the modern experience. For this, I seek to introduce the reader in the discussion from the historian's thinking Reihart Koseleck about modern temporality, and from this point of view try to shed light on the conceptions about the modern world in the three classical authors mentioned

Keywords: Modernity; Weber; Durkheim; Tocqueville.

\section{Introdução}

Que seria a modernidade? Essa é uma pergunta a qual muitos autores de diferentes ramos das ciências humanas se debruçaram em busca de resposta. Pode a modernidade ser definida a partir do humanismo, da separação do ser humano e da natureza, da aceleração do tempo histórico, do surgimento e difusão das filosofias da história, ou ainda, identificando a modernidade com o capitalismo e as transformações ocorridas

\footnotetext{
${ }^{1}$ Formado em Direito pela UFRJ e licenciado em Ciências Sociais também pela UFRJ. Mestre em Ciência Política pela UFF. Doutorando em Sociologia pelo IESP-UERJ. Contato: reenan.carvalho@gmail.com.
} 
com as revoluções sociais e tecnológicas do último quarto do segundo milênio. Todas essas definições têm, ao mesmo tempo, um quê de arbitrariedade e de perspicácia. Algo de criatividade e de fidelidade à observação e descrição do que se passa com o mundo.

\begin{abstract}
A modernidade possui tantos sentidos quantos forem os pensadores ou jornalistas. Ainda assim, todas as definições apontam, de uma forma ou de outra, para a passagem do tempo. Através do adjetivo moderno, assinalamos um novo regime, uma aceleração, uma ruptura, uma revolução no tempo. Quando as palavras "moderno", "modernização", e "modernidade" aparecem, definimos, por contraste, um passado arcaico e estável (LATOUR, 1994, p. 15).
\end{abstract}

Seja qual for a chave interpretativa que possamos escolher para tentar definir ou entender o que seria a modernidade, podemos concordar que se trata de uma época, um tempo ou uma temporalidade que se constitui a partir de uma contraposição com a ideia de antiguidade. Os "modernos" são modernos porque são diferentes em algum sentido do que eram os "antigos". Mas, em que consiste esta diferença? Como podemos identificar o que separa o ser humano "moderno" do "antigo"?

É atravessado por essas questões que buscaremos esboçar uma concepção de modernidade que a nosso ver pode servir de fio condutor para analisarmos as diferentes representações e entendimentos acerca desta temporalidade ou deste processo denominado de "modernidade" por parte de três clássicos da sociologia: Alexis de Tocqueville, Émile Durkheim e Max Weber. Nela, percebemos uma transformação fundamental na forma como a civilização ocidental passou a perceber o tempo histórico e a estabelecer sua relação com ele.

A concepção da História como mestra da vida (em latim, Historia Magistra Vitae) foi por muito tempo aquela que orientou a percepção do tempo histórico na civilização ocidental. Nela está contida a ideia de que a(s) história(s) tem um caráter pedagógico, pois sua observação pode sempre servir de aprendizado e ser utilizada para a resolução das questões que possam surgir no contexto da vida individual e coletiva. Sob esta perspectiva, a história representa um ciclo, onde todas as experiências voltariam a acontecer de uma forma diferente, porém comparável às experiências já ocorridas e observadas no passado.

Para ilustrar a transformação ocorrida na perspectiva do tempo histórico, 
Reinhart Koselleck, em sua obra "Futuro Passado: Contribuição à semântica dos tempos históricos", começa por descrever o quadro de Albercht Altdorder, "Batalha de Alexandre", onde é retratada a Batalha de Issus (ocorrida no ano de 333a.c) entre Alexandre, o Grande e o exército Persa de Dário III. Entretanto, segundo Koselleck:

\begin{abstract}
Quando contemplamos o quadro na Pinacoteca de Munique, somos confrontados com mais um anacronismo notável: acreditamos ver à nossa frente Maximiliano, o último cavaleiro, e as hordas de lansquenetes da Batalha de Paiva. A maioria dos persas assemelha-se, dos pés aos turbantes, aos turcos, que, no mesmo ano da composição do quadro (1529), sitiaram Viena, sem resultado. Em outras palavras, Altdorfer captou um acontecimento histórico que era, ao mesmo tempo, contemporâneo para ele. Alexandre e Maximiliano (Altdorfer pintou o quadro para este último) assemelham-se de maneira exemplar. O espaço de experiência nutria-se, portanto, da perspectiva de uma única geração histórica (KOSELLECK, 2006, p. 22).
\end{abstract}

É através da descrição dos anacronismos presentes nesta obra de arte, bem como de uma minuciosa análise acerca da semântica historicamente atribuída à palavra "história", que Koselleck pretende introduzir o leitor a sua tese acerca do conceito de modernidade.

A escolha da obra, por seu caráter ambíguo em relação a temporalidade da narrativa nela retratada busca, de fato, destacar a atemporalidade do quadro de Albercht Altdorder para seus contemporâneos. A observação de que o estado das técnicas de guerra à época em que o quadro foi pintado não diferia tanto daquelas da antiguidade, dos tempos de Alexandre o Grande já é, em si, bastante contundente. Mas não é só isso. Koselleck (2006) convida o leitor a observar a tela com os olhos de um contemporâneo da obra e descreve a representatividade dos elementos ali dispostos para com as profecias acerca do fim dos tempos - muito em voga durante toda idade média e também no século XVI. "A história da cristandade, até o século XVI, é uma história das expectativas, ou melhor dizendo, de uma contínua expectativa do final dos tempos" (KOSELLECK, 2006, p. 24).

Dessa forma o autor pretende demonstrar que, para os contemporâneos de Albercht Altdorder, aquela imagem representaria tanto uma narrativa passada como um acontecimento histórico presente e, possivelmente, uma representação da futura grande batalha pré-apocalíptica. "A Batalha de Alexandre era atemporal como modelo, como figura ou arquétipo de uma luta final entre Cristo e Anticristo; os que lutavam ali eram 
contemporâneos de todos aqueles que viveram aguardado o Juízo Final" (KOSELLECK, 2006, p. 24).

Ao analisar o comentário que Friedrich Schlegel, poeta e crítico literário alemão que viveu entre os séculos XVIII e XIX, fez ao observar a obra de Altdorfer, descrevendo a imagem como "a mais sublime aventura da antiga cavalaria"; e com isso, conferindo a ela distância histórica em relação ao presente, Koselleck percebe uma diferença em relação a dimensão especificamente temporal que se estabelece entre Schlegel e Altdorfer. Para o autor, nos trezentos anos que os separam transcorreu mais tempo, ou melhor, um tempo de natureza diferente daquele que transcorrera entre Altdorfer e a Batalha de Issus, por ele representada em seu quadro (KOSELLECK, 2006).

Esta diferença na perspectiva em relação ao tempo histórico, ou essa temporalização da história, marca a ruptura com a perspectiva cíclica da história, ou da percepção dominante onde "presente e passado estariam (...) circundados por um horizonte histórico comum"(KOSELLECK, 2006, p. 22). A ideia de Leibniz de que "O mundo que está por vir já se encontra embutido no presente, completamente modelado" (KOSELLECK, 2006, p. 24), é expressão desta perspectiva que, dentro do âmbito da política, tinha como método o prognostico racional, a ser realizado através da soma entre a análise de conjuntura política da época com as lições apreendidas pelo estudo da história e de seus exemplos. Foi Maquiavel o exemplo clássico e talvez o mais notório filósofo a se utilizar do método do prognóstico racional baseando-se na concepção circular do devir político. Ao descrever a política, Maquiavel busca estabelecer paradigmas para a atuação política segundo as lições oferecidas pelos exemplos históricos. Está aí contida a essência da concepção da História como mestra da vida.

Nem é por acaso, nem sem motivo, que os sábios costumam dizer: basta considerar o que foi para saber o que será. De fato, em todas as épocas o que acontece neste mundo tem analogia com o que já aconteceu (MAQUIAVEL, 1994, p. 423).

O advento da modernidade representa uma transformação na forma como o homem se relaciona com o tempo. Se antes a história² era uma palavra que representava

${ }^{2}$ Em alemão "Historie" sendo um termo usado no plural, pois designava narrativas particulares e descosidas entre si. $\mathrm{O}$ advento da modernidade pode ser percebido também pela semântica 
as narrativas sobre os fatos que aconteceram e que poderiam ser objeto de análise e reflexão para iluminar o presente e o futuro, com o tempo ela passa a designar a história da humanidade como um todo. A marcha do ser humano desde sua criação até os dias atuais. A metáfora espacial que melhor ilustra este processo é a ruptura da concepção cíclica da história para uma forma de percepção progressiva e linear do tempo. A história passa a ser apreendida como a marcha da humanidade, uma linha reta em direção ao futuro e ao progresso.

Segundo Koselleck (2006, p. 35), "foi só com o advento da filosofia da história que uma incipiente modernidade desligou-se de seu próprio passado, inaugurando, por meio de um futuro inédito, também a nossa modernidade”. Para o autor, é apenas a partir da ideia de progresso e de um consequente distanciamento entre o futuro e o passado que se pode pensar a temporalidade moderna. Tal distanciamento entre o que o autor chama de espaço de experiência e horizonte de expectativa se estabelece com as transformações ocorridas nas sociedades ocidentais a partir, principalmente, da revolução industrial e da Revolução Francesa. A possibilidade do inédito marca o rompimento entre o passado e o futuro. A aceleração do tempo histórico permite um crescente distanciamento entre espaço de experiência do passado e horizonte de expectativa de futuro. Como resultado disto, a cada nova geração, cresce de sobremaneira a possibilidade do novo e a concepção da história passa a ser orientada pela ideia de um progresso que se busca indefinidamente, como um horizonte a ser “alcançado".

Por este processo, a história deixa de ser a mestra da vida para ser percebida como um processo que pode ser apreendido e dotado de sentido. A filosofia da história surge como expressão deste processo, onde ao mesmo tempo em que o futuro deixa de se referir as experiências passadas ele passa a poder ser objeto de uma construção planejada. Passado, presente e futuro aparecem como uma totalidade, um processo progressivo capaz de ser conformado e moldado a partir da ação humana. A ideia de modernidade está contida justamente nessa indeterminação em relação ao futuro que a

historicamente atribuída a palavra história no alemão, que antes designava narrativas desligadas uma das outras - a guerra do Peloponeso, a história da igreja, ou a vida de Jesus Cristo. Com o tempo, Historie é substituído por "Geschinte" que designa uma sequência unificada de eventos que, vistos como um todo, constituem a marcha da humanidade (KOSELLECK, 2006). 
aceleração das transformações sociais conformou.

A descrição da distância histórica conferida por Friedrich Schlegel à pintura do quadro "Batalha de Alexandre" ilustra essa aceleração do tempo histórico demarcada por Koselleck como expressão da modernidade. Um tempo onde a distância entre o espaço de experiência e o horizonte de expectativa aumentam progressivamente, em concomitância com as grandes transformações ocorridas na sociedade. Neste sentido, a partir de agora importará pensar como os três autores clássicos da sociologia assinalados - Max Weber, Émile Durkheim e Alexis de Tocqueville - interpretaram a então inédita sensação de viver em um mundo no qual a estabilidade fincada na tradição fora deslocada em prol de uma realidade em constante transformação. Um mundo novo que não se referia mais necessariamente ao passado e onde, nas palavras do também clássico da sociologia Karl Marx (2005, p. 43), "tudo que é sólido e estável se desmancha no ar".

\section{Durkheim e a Modernidade como Diferenciação.}

Émile Durkheim foi um sociólogo francês nascido em Epinal, cidade francesa da região da Lorena, em 1858. É até hoje considerado um dos maiores autores clássicos da sociologia, tendo contribuído muito para a constituição da sociologia com uma ciência autônoma. Entendia que a sociologia era a ciência a estudar as instituições - entendidas como crenças e modos de conduta estabelecidos pela coletividade -, sendo seu objeto de estudo primordial todos aqueles fatos que pudessem ser considerados como fatos sociais. $^{3}$

Em sua obra, Durkheim está preocupado com os efeitos que as transformações sociais ocorridas com o advento da modernidade estariam causando na constituição moral do homem moderno e na coesão do corpo social. É a partir do fenômeno da divisão do trabalho social que ele busca apreender esse processo e explicar suas consequências.

Durkheim elabora uma teoria funcionalista e estrutural da sociedade. Segundo

3 Os fatos sociais seriam as formas de pensar, agir e sentir que são ao mesmo tempo, exteriores ao indivíduo, gerais na sociedade ou em determinados grupos sociais, e coercitivos, uma vez que expressam estados da consciência coletiva que penetram nos indivíduos com um caráter normativo, conformando suas ações em sociedade. 
sua perspectiva, a divisão do trabalho social significa especialização funcional. Cada indivíduo, inserido em uma sociedade cada vez mais complexa e diversificada está nela inserido de modo a exercer uma função dentro do organismo social. Este fenômeno cada vez mais aprofundado e difundido na ordem social moderna tem efeitos muito além daqueles observados no incremento da produção e da economia. A divisão do trabalho tem um caráter moral. Uma vez que gera consequências na forma como a sociedade se organiza e na consciência coletiva que a conforma.

Neste sentido, em sua obra "Da divisão do trabalho social” tese de doutoramento publicada em 1893, Durkheim pretende demonstrar como a divisão do trabalho se torna o principal fator de coesão social nas sociedades modernas. Para ilustrar essa transformação e expressar sua perspectiva acerca de seus efeitos na conformação da sociedade moderna, o autor busca contrapor a sociedade moderna às sociedades tidas como "inferiores" ou "primitivas". Neste ponto fica muito clara sua imersão na lógica que percebe uma linha progressiva no desenvolvimento histórico das sociedades humanas. Para ilustrar como se articulam a ideia de modernidade ligada ao progresso e a divisão do trabalho social Durkheim dispõe:

Somos levados, assim, a nos perguntar se a divisão do trabalho não desempenharia o mesmo papel em grupos mais extensos, se, nas sociedades contemporâneas, em que teve o desenvolvimento que sabemos, ela não teria a função de integrar o corpo social, assegurar sua unidade. É legítimo supor que os fatos que acabamos de observar se reproduzem nelas, mas com maior amplitude; que essas grandes sociedades políticas também só se podem manter em equilíbrio graças à especialização de tarefas; que a divisão do trabalho é a fonte, se não única, pelo menos principal de solidariedade social. (DURKHEIM, 1995, p. 29).

E, citando Augusto Comte, continua:

Já foi nesse ponto de vista que Comte se colocou. De todos os sociólogos, a nosso conhecimento, ele foi o primeiro a assinalar na divisão do trabalho algo mais que um fenômeno puramente econômico (...). Considerada por esse aspecto a divisão do trabalho, diz ele "leva imediatamente a encarar não apenas os indivíduos e as classes, mas também, sob muitos aspectos, os diferentes povos, como participantes, ao mesmo tempo e de acordo com um modo próprio e um grau especial, exatamente determinados, de uma obra imensa e comum, cujo inevitável desenvolvimento gradual também liga, aliás, os atuais cooperadores à série de seus predecessores e mesmo à série de seus sucessores. Portanto, é a repartição contínua dos diferentes trabalhos humanos que constitui principalmente a solidariedade social e que se torna a causa elementar 
da extensão e da complicação crescente do organismo social". (DURKHEIM, 1995, p. 29).

É a partir da criação de algumas categorias e de sua instrumentalização na observação das dinâmicas da sociedade que Durkheim busca explicar no que consiste a mudança estabelecida pelo fenômeno da divisão do trabalho social, e quais suas consequências para a sociedade, principalmente no tocante a coesão social. Segundo o autor: "O conjunto das crenças e dos sentimentos comuns à média dos membros de uma mesma sociedade forma um sistema determinado que tem vida própria; podemos chama-lo de consciência coletiva ou comum" (DURKHEIM, 1995, p. 50). A solidariedade social adviria dessa consciência coletiva, como aspecto que integra a sociedade, garantindo sua coesão. Seria o elemento social que estabelece nos indivíduos o sentimento de que integram uma mesma comunidade, seja pela sua semelhança ou pela sua interdependência.

Nas sociedades que designa como "primitivas" ou "inferiores", pautadas nos costumes, na tradição, em economias predominantemente agrárias e onde a religião ocupa um papel determinante na conformação e organização do corpo social, a consciência coletiva teria uma grande força sobre a individualidade dos seus membros. Estas sociedades teriam a divisão do trabalho social pouco difundida e diversificada, o que implicaria na conformação de sociedades mais simples que as modernas e sem grandes diferenciações entre seus membros. Durkheim (1995) assevera que a solidariedade que garantiria a coesão neste tipo de formação social seria a solidariedade "mecânica" ou por similitude. Isto porque nelas, o elemento que garantiria a coesão da sociedade seria justamente a semelhança entre os membros do corpo social, e o fato desta semelhança expressar uma forte uniformidade na consciência coletiva.

Em contraponto à solidariedade mecânica fundada na semelhança entre os membros do corpo social e que garantiria a coesão social nas sociedades primitivas e sem uma grande divisão social do trabalho, haveria se conformado uma nova forma de solidariedade social nas sociedades modernas, a solidariedade orgânica. A solidariedade orgânica seria substrato da divisão do trabalho social e derivaria do crescente processo de especialização funcional ao qual os indivíduos passaram com o advento da modernidade. Essa solidariedade se conforma a partir da interdependência entre os 
membros do corpo social, uma vez que cada indivíduo seria instado a se especializar cada vez mais em apenas uma função e, portanto, passaria a depender dos outros membros do corpo social, gerando um sentimento de pertencimento à sociedade por interdependência (DURKHEIM, 1995).

Do mesmo modo, a especialização gerada pela crescente divisão do trabalho social gera a possibilidade de constituição do indivíduo de forma cada vez mais autônoma em relação à sociedade. Segundo Durkheim (1995), à medida que a divisão social do trabalho vai se tornando uma característica mais marcante e presente nas sociedades, abre-se o espaço para a personalidade individual, que se sobrepõe de forma progressiva à semelhança entre os membros da comunidade observada nas ditas "sociedades inferiores". Essas transformações possibilitaram o surgimento de novas formas de viver que não eram possíveis antes da emergência desse processo.

Entretanto, segundo Durkheim (1995), apesar da divisão do trabalho ser o elemento conformador da solidariedade social nas sociedades modernas - a solidariedade orgânica - as mudanças ocorridas na sociedade em função da divisão do trabalho se deram muito mais rápido do que as regulações estabelecidas para normatizar e ordenar essas mudanças. Neste sentido, Durkheim percebe que haveria um estado de anomia, ou desordem que põe em risco a coesão social. Isto poderia ser observado ao analisar a taxa de suicídio de uma dada sociedade, onde as sociedades modernas teriam, segundo suas análises, taxas de suicídio maiores do que as sociedades "primitivas". Em sua explicação acerca deste fenômeno, Durkheim indica que é a falta de instituições e normas reguladoras que permitem a existência de um processo de anomia. Para ele, se as instituições reguladoras como o Estado estivessem cumprindo adequadamente suas funções de coordenação e regulação da sociedade, a solidariedade advinda da divisão do trabalho social poderia se expressar gerando harmonia social.

Portanto, podemos dizer que a modernidade seria para Durkheim um tempo onde a diferenciação entre as pessoas causada pelo incremento e diversificação da divisão do trabalho social formariam novas relações sociais e novos indivíduos, muito mais autênticos do que aqueles conformados pelas relações sociais estabelecidas nas sociedades ditas "primitivas" ou "inferiores". Esse seria um tempo de relações sociais muito mais complexas, o que conformaria um ambiente propício para o florescimento 
da personalidade individual. Uma sociedade onde a diferenciação entre as pessoas seria a característica marcante e onde através deste processo de grandes transformações estaria surgindo uma nova solidariedade, fundada na interdependência entre os indivíduos que integram o corpo social.

\section{Weber e a Modernidade como Racionalização.}

Max Weber foi um sociólogo, jurista e economista alemão, considerado um dos fundadores da sociologia. Nasceu em Erfurt, no antigo Reino da Prússia, em 1864. Estudou história, economia e direito nas universidades de Heidelberg e Berlim, e exerceu a docência nas universidades de Freiburg e, principalmente, Heidelberg. Em sua obra, realizou um esforço para a compreensão de fenômenos históricos e sociais, além de uma reflexão acerca do método nas ciências sociais.

A questão da modernidade perpassa a obra de Weber a partir do paradigma da racionalização. Para Weber a característica distintiva da modernidade seria o processo de racionalização da vida e desencantamento do mundo que a sociedade ocidental havia experimentado. Segundo Habermas, "Para Max Weber ainda era evidente a relação interna, e não a meramente contingente, entre a modernidade e aquilo que designou como racionalismo ocidental" (HABERMAS, 2000, p. 3). Em linhas gerais, entende-se que o conceito de racionalização, como utilizado por Weber, significa a redução à racionalidade de todos os aspectos da vida social. Quando trata do processo de racionalização da vida, o autor busca descrever o processo por meio do qual, nas sociedades ocidentais, as ações sociais dos indivíduos passam a ser orientadas não mais a partir de motivações tradicionais e afetivas - baseadas nos costumes, tradições ou sentimentos - mas a partir de uma lógica estritamente racional, seja quanto aos valores ou, principalmente, em relação aos fins (WEBER, 1994). ${ }^{4}$

Sobre o processo de racionalização em Weber, Habermas descreve:

O que Max Weber descreveu do ponto de vista da racionalização não foi apenas a profanação da cultura ocidental, mas, sobretudo, o desenvolvimento das sociedades modernas. (...) Weber entende esse processo como a

4 Nesse sentido, a racionalização ofereceria as condições nas quais a ação social é exercida. A racionalização é o processo que confere significado à diferenciação entre as linhas de ação. 
institucionalização de uma ação econômica e administrativa racional com respeito a fins. À medida que o cotidiano foi tomado por esta racionalização cultural e social, dissolveram-se também as formas de vida tradicionais, que no início da modernidade se diferenciaram principalmente em função das corporações de ofício (HABERMAS, 2000, p. 3).

Ao lado do processo de racionalização e - em parte 5 - concomitante a ele, estaria um outro processo, denominado por Weber de desencantamento do mundo. $\mathrm{O}$ desencantamento do mundo é identificado como um processo histórico-religioso ocorrido na civilização ocidental, onde, a partir das profecias do judaísmo antigo, ocorre uma desmagificação das religiões, ou seja, a construção de uma religiosidade que vai suprimindo cada vez mais a magia como elemento sacramental da religiosidade. Com o processo de desencantamento, cada vez mais o mundo deixa de ser concebido como permeado por forças ocultas que podem ser manipuladas através de rituais e feitiços, e a magia que passa a ser repudiada como superstição e sacrilégio (WEBER, 2004, p. 96). Tal processo segue com o pensamento cientifico-filosófico do período helenístico e tem seu apogeu com o protestantismo ascético, que, segundo Weber (2004), tem grande influência na conformação do capitalismo.

É em sua obra "A ética protestante e o "espírito" do capitalismo", que Weber vai buscar demonstrar como se deu o processo no qual a ética estabelecida por determinadas denominações protestantes convergira com certos comportamentos econômicos de forma a proporcionar - por meio de uma teologia que se constituía a partir da união de elementos de racionalização da vida e desencantamento do mundo condições favoráveis para o desenvolvimento do capitalismo. É a partir da angustia pela salvação trazida pela doutrina teológica da predestinação, aliada a elementos que identificavam na ética do trabalho, na vocação profissional e no ascetismo uma forma de condução da vida, que o protestantismo do calvinismo e de outras orientações "puritanas" conformaram uma forma de vida que ensejou tanto um processo de

\footnotetext{
${ }^{5}$ Em parte, pois o processo de desencantamento do mundo seria anterior a este processo de racionalização da vida no mundo ocidental. Uma vez que, como visto, tem início ainda na antiguidade com a conformação das religiões judaicas e prossegue até a modernidade. De certo modo, o processo de racionalização é também anterior ao advento da modernidade, uma vez que não se pode dissocia-lo completamente do desencantamento do mundo. O que é característico da modernidade é a predominância cada vez mais acentuada de uma racionalidade instrumental, ligada a ação social com relação aos fins.
} 
acumulação de capital, quanto a conformação de um "espírito do capitalismo". 6 "Essa racionalização da conduta de vida no mundo, mas de olho no Outro Mundo é o efeito da concepção de profissão do protestantismo ascético” (WEBER, 2004, p. 139).

Neste sentido, segundo Weber, os processos de racionalização da vida e desencantamento do mundo estariam profundamente imbricados, sendo ambos fundamentais para a conformação daquilo que entendemos como modernidade.

\begin{abstract}
A intelectualização e a racionalização geral não significam, pois, um maior conhecimento geral das condições da vida, mas algo de muito diverso: o saber ou a crença em que, se alguém simplesmente quisesse, poderia, em qualquer momento, experimentar que, em princípio, não há poderes ocultos e imprevisíveis, que nela interfiram; que, pelo contrário, todas as coisas podem em princípio - ser dominadas mediante o cálculo. Quer isto dizer: o desencantamento do mundo. Diferentemente do selvagem, para o qual tais poderes existem, já não temos de recorrer a meios mágicos para controlar ou invocar os espíritos. Isso consegue-se graças aos meios técnicos e ao cálculo. Tal é, essencialmente, o significado da intelectualização (WEBER, 2010, p. 30-31).
\end{abstract}

Em sua obra, Weber demarca a importância e o papel das ideias na construção histórica e na transformação e conformação da realidade. É através da ideia de racionalização que busca entender e explicar ao longo de suas obras os processos de transformação que ensejaram a conformação de realidades até então inéditas como o desenvolvimento das ciências, a centralização estatal e a formação de sua burocracia e até a própria formação da sociedade capitalista. Através de seus escritos podemos perceber sua posição acerca da tendência ao aprofundamento destes processos, percebendo-os como quase inevitáveis, e alertando para a falta de sentido e o mal-estar que poderiam ocasionar à existência do homem moderno. A ideia de que na modernidade o ser humano estaria preso a uma "jaula de ferro" - na célebre tradução de Talcott Parsons -, ou em uma "crosta de aço", que nos prenderia a uma lógica que percebe a acumulação de bens materiais como o fim último da existência e, com isso, negaria ao ser humano a possibilidade de atribuir outros sentidos a sua própria existência (WEBER, 2004, p. 165).

\footnotetext{
${ }^{6}$ Por "espírito do capitalismo", devemos entender a conformação de um "ethos", "uma ideia do dever que tem o indivíduo de se interessar pelo aumento de suas posses com um fim em si mesmo" que se conforma assumindo "o caráter de uma máxima de conduta de vida eticamente coroada" (Weber, 2004, p. 45).
} 
Ninguém sabe ainda quem no futuro vai viver sob essa crosta e se ao cabo do desenvolvimento monstro hão de surgir profetas inteiramente novos (...). Então, para os 'últimos homens' desse desenvolvimento cultural, bem poderiam tornar-se verdades as palavras: "Especialistas sem espírito, gozadores sem coração: esse Nada imagina ter chegado a um grau de humanidade nunca antes alcançado" (WEBER, 2004, p. 166, grifo do autor).

Apesar de não adentrar nessa discussão mais a fundo - o que, segundo o autor, seria fugir ao tema de sua pesquisa, uma vez que adentraria assim no terreno dos juízos de valor e de fé -, Weber nos dá elementos para perceber na racionalização um processo cujo aprofundamento possibilita a conformação de mudanças materiais e culturais na sociedade, mas que ao mesmo tempo enseja certo "aprisionamento" da subjetividade humana. Aqui, o ineditismo das transformações realizadas pelo aprofundamento deste processo não se refere necessariamente à liberdade da condição humana. A modernidade enseja mudança social, ainda que as custas ou a despeito da liberdade.

(...) esse poderoso cosmos da ordem econômica moderna ligado a pressupostos técnicos e econômicos da produção pela máquina, que hoje determina com pressão avassaladora o estilo de vida de todos os indivíduos que nascem sobre essa engrenagem - não só dos economicamente ativos - e talvez continue a determinar até que cesse de queimar a última porção de combustível fóssil. (WEBER, 2004, p. 165).

Estes são, em linhas gerais e de forma sucinta, os principais aspectos da concepção Weberiana acerca da modernidade. Ao estabelecer uma concepção do capitalismo como cultura e perceber na racionalização o elemento fundamental a caracterizar a modernidade, Weber nos fornece uma importante contribuição para interpretar esses "novos tempos". Interessante para o nosso estudo também o fato de perceber na modernidade um tempo de transformações inéditas na história - tanto de cunho material quanto cultural -, bem como o fato de realizar prognósticos em relação ao futuro, como por exemplo, ao indicar como praticamente inevitável o desenvolvimento do processo de racionalização da vida e ao perceber certo o mal-estar em relação ao futuro a partir as transformações que observa acontecerem em seu tempo histórico. 


\section{Tocqueville e a Modernidade como Igualdade.}

Alexis de Tocqueville foi um pensador político, magistrado, historiador e escritor francês. Nasceu em Paris, no ano de 1805, no seio de família aristocrática francesa. Foi magistrado entre os anos de 1827 e 1839, ano em que foi eleito deputado, posição que ocupou durante boa parte da monarquia de junho. Embora fosse um pensador imbuído de ideias eminentemente liberais, nunca abandonou por completo certos valores e concepções da tradição aristocrática, podendo ser identificado hoje como um liberal conservador - apesar do fato de que, em seu tempo, no parlamento ter se identificado à centro-esquerda do espectro político.

O autor procura observar e descrever as transformações ocorridas com o advento da modernidade, identificando na Igualdade o elemento mais distintivo deste novo tempo histórico. É na obra "A democracia na América”, onde Tocqueville faz suas principais observações acerca das transformações ocorridas em seu tempo histórico e, a partir delas, pautado no que vê em sua volta, busca fazer prognósticos sobre para onde andaria a marcha da história. Ao comparar as transformações ocorridas na França de seu tempo - com o declínio das sociedades tradicionais pautadas na tradição, na estratificação social e nos privilégios de nascimento durante o longo processo da Revolução Francesa - com o que observou acerca da sociedade americana em viagem que fez aos Estados Unidos, Tocqueville aponta que: "Uma grande revolução democrática acha-se em curso entre nós" (TOCQUEVILLE, 1977, p. 11).

Entre os objetos novos que, durante a minha demora nos Estados Unidos, atraíram a minha atenção, nenhum me impressionou mais vivamente do que a igualdade de condições. Não me custou perceber a influência prodigiosa que essa realidade primária exerce sobre a marcha da sociedade; (...). Logo reconheci que esse mesmo fato se estende a sua influência para muito além dos costumes políticos e das leis e que não tem menos domínio sobre a sociedade civil do que tem sobre o governo; cria opiniões, faz nascer sentimentos, sugere práticas e modifica tudo aquilo que ele mesmo não produz. Dessa forma, à medida que estudava a sociedade americana, via cada vez mais na igualdade de condições, o fato essencial do qual parecia descender cada fato particular, e o encontrava constantemente diante de mim, como um ponto de convergência para todas as minhas observações. Voltei meu pensamento para o nosso hemisfério e pareceu-me distinguir nele algo de semelhante ao espetáculo que me oferecia o Novo Mundo. Vi a igualdade de condições que, sem nele ter chegado, como nos Estados Unidos, aos seus limites extremos, se aproximava cada dia mais desses limites; e aquela mesma 
democracia que reinava sobre a sociedade americana parecia-me encaminhar-se rapidamente para o poder, na Europa (TOCQUEVILLE,1977, p. 11, grifo do autor).

Para Tocqueville (1977), o século XIX poderia ser descrito com o "século da igualdade”. Essa igualdade da qual se refere quer dizer muito mais igualdade de condições entre todos os indivíduos do corpo social do que propriamente igualdade material entre eles. Se expressa politicamente no caráter democrático da organização social. Esse contraponto entre a igualdade de condições das sociedades democráticas e a desigualdade que é constitutiva das sociedades aristocráticas pautadas no privilégio hereditário do antigo regime é fundamental para entender a marcha histórica a qual, segundo o autor, caminha a humanidade. Entre suas observações, prevê que a democracia caminha para se estabelecer como regime político das sociedades modernas, sendo que o poder monárquico e as instituições e relações sociais tradicionais seriam transformadas por essa marcha histórica que moldaria as sociedades, suas instituições e costumes cada vez mais no sentido da democracia e da igualdade. $\mathrm{O}$ autor aborda as potencialidades dessas transformações, fazendo prognósticos acerca do que poderia vir a ocorrer com as sociedades que caminhassem neste sentido. Tocqueville (1977) prevê as sociedades de massa, onde reina a igualdade e, com ela, o consenso. Um Estado democrático tenderia, assim, a concentrar poderes e controlar vontades. Não da forma vista sob os regimes despóticos ou absolutistas de seu tempo. Mas de uma forma sutil e constante. Um tipo de organização social e do poder onde o Estado se encarrega de prever e prover as necessidades e regular a vida dos cidadãos, mas também, de tutelar suas vontades e controla-los em seus desígnios e em diversos aspectos de suas vidas.

Outro perigo que existe na constituição de regimes democráticos e fundados eminentemente na igualdade seria a tirania da maioria. Essa forma de tirania seria própria das democracias e da força que a vontade da maioria extraí dessa forma de governo (TOCQUEVILLE, 1977). Por isso, alerta para a perseguição das minorias que venham a, por ventura, se opor à vontade soberana da maioria. Apesar das críticas e alertas sobre os perigos que o futuro poderia reservar às sociedades modernas, Tocqueville entende com positivas - e inevitáveis - muitas das mudanças efetivadas pela igualdade democrática, que ao estabelecer igualdade de condições entre os indivíduos, 
superavam muitas das injustiças que marcavam as sociedades aristocráticas tradicionais.

Ao longo da obra, além de tentar explicar como funcionava a sociedade e os costumes do povo norte americano, Tocqueville procura encontrar maneiras de entender como foi possível a conformação de uma sociedade tal qual aquela que ele observava nos Estados Unidos de 1830. Para isso, buscou na história da formação social dos Estados Unidos uma dentre as razões para a conformação da sociedade que observava na América. Entretanto, apesar de buscar explicar a formação social a partir de certas condições históricas de organização social que naquele lugar se deram condições que foram originais, uma vez que nenhum outro pais tinha se formado a partir de condições semelhantes - considera que apenas a história não seria suficiente para lançar luz a todas as transformações que se perfaziam naquela sociedade, pela complexidade e pelo caráter inédito daquela experiência de conformação social.

Antes de abandonar definitivamente o caminho que acabo de percorrer,
desejaria poder abranger com um derradeiro olhar, todos os diversos
traços que marcam a face do mundo novo e, por fim, julgar a influência
geral que a igualdade deve exercer sobre a sorte dos homens; (...) Essa
sociedade nova que procurei retratar e que desejo julgar mal acabou de nascer.
O tempo ainda não definiu a sua forma, grande revolução que a criou dura ainda
e é quase impossível, no que ocorre hoje em dia, discernir o que deve passar
com a própria revolução e o que ficará depois dela. O mundo que surge está
ainda meio preso sob os destroços do mundo que desaparece e em meio a
imensa confusão que os assuntos humanos apresentam, ninguém seria capaz
de dizer o que ficará de pé das velhas instituiçães e dos velhos costumes, e o
que virá finalmente a desaparecer. Embora a revolução que se opera na situação
social, nas leis, nas ideias, nos sentimentos dos homens, esteja ainda longe de
terminar, já não seria mais possível já não seria mais possível comparar as suas
obras a coisa alguma do que já se viu no mundo. Remontando, de século em
século, à Antiguidade mais remota, nada percebo que se assemelhe ao
que tenho diante dos olhos. Como o passado já não esclarece o futuro, o
espírito marcha nas trevas (TOCQUEVILLE,1977, p. 540 , grifo do autor).

É nesse sentido que Tocqueville representa a modernidade, como um tempo de transformações em direção ao mesmo tempo à igualdade e ao desconhecido. Uma temporalidade e uma experiência histórica que não encontra precedentes onde nós possamos nos basear. Algo de inevitável leva a humanidade neste caminho, sendo os Estados Unidos apenas o primeiro dentre os países a concretizar esta experiência de forma mais contundente. 


\section{Considerações finais}

A aceleração do tempo histórico e a percepção de que a humanidade estaria caminhando para uma experiência inédita na história, sem referência a qualquer experiência já estabelecida no passado são elementos que permitem a esses autores perceber a modernidade como uma ruptura com o passado. Ao analisar as concepções acerca da modernidade em Tocqueville, Durkheim e Weber, podemos perceber que todos estes autores, a despeito das especificidades em relação as suas concepções acerca do fenômeno, estão imersos na forma como a civilização ocidental passou a perceber o tempo histórico e a estabelecer sua relação com ele.

O distanciamento entre o espaço de experiência e horizonte de expectativa, tal qual descrito por Koselleck (2006) como elemento constitutivo da modernidade, pode ser percebido em suas obras, a partir tanto das potencialidades que as transformações que estabelecem a modernidade ensejam, quanto a suas preocupações em relação aos aspectos perigosos dessas transformações. A anomia, que segundo Durkheim (1995) poria em risco a coesão social. A perda de sentido da vida, que Weber (2004) observa com preocupação, que teria aprisionado seu espírito em uma "jaula de ferro" e faria a existência humana perder qualquer valor ou significado. Ou, como nos alerta Tocqueville (1977), os riscos que a democracia e a igualdade poderiam esconder no futuro, com a tirania da maioria e a perda de liberdade que o despotismo e a centralização poderiam fazer emergir.

Seja a partir do paradigma da diferenciação, como em Durkheim, da racionalização, tal qual Weber, ou da igualdade como faz Tocqueville, todos estes autores clássicos da sociologia percebem a modernidade como um tempo de mudanças incontornáveis, às quais o passado já não pode servir como referência para orientação de conduta. Trata-se da formação de um mundo novo, onde ao mesmo tempo em que se sabe que algo está se perdendo, não se sabe ao certo aquilo que poderá advir das transformações que estão sendo observadas. É nesse sentido que percebemos suas contribuições em relação a sociologia como um esforço, uma forma de tentar apreender esse movimento, essas transformações que ao mesmo tempo assustam e encantam pela força do desconhecido que o futuro enseja. Um tempo onde, como aponta Tocqueville: 
“Como o passado já não esclarece o futuro, o espírito marcha nas trevas".

\section{Referências}

DURKHEIM, Émile. Da divisão do trabalho social. São Paulo: Martins Fontes, 1995.

HABERMAS. Jürgen. O discurso filosófico da modernidade: doze lições. São Paulo: Martins Fontes. 2000.

KOSELLECK, Reinhart. Futuro Passado. Contribuição à semântica dos tempos históricos. Rio de Janeiro: Contraponto, Editora Puc-RJ, 2006.

LATOUR, Bruno. Jamais fomos modernos: ensaios de antropologia simétrica. Rio de Janeiro. Ed 34, 1994.

MAQUIAVEL, Nicoláu. Comentários sobre a primeira década de Tito Lívio. Brasília, Editora Universidade de Brasília, 1994.

MARX, Karl; ENGELS, Friedrich. Manifesto comunista. São Paulo: Boitempo, 2005.

PIERUCCI, A. F. O Desencantamento do mundo: Todos os passos do conceito em Max Weber. São Paulo: Editora 34, 2003.

SELL, Carlos Eduardo. Max Weber e a racionalização da vida. Petrópolis: Vozes, 2013. TOCQUEVILLE, Alexis de. A democracia na América. São Paulo, ed. Universidade de São Paulo, 1977.

WEBER, Max. A ética protestante e o "espírito" do capitalismo. São Paulo: Companhia das Letras, 2004.

Ciência e política, duas vocações. São Paulo, Cultrix, 2010.

Economia e Sociedade. Brasília - DF: Editora da Universidade de Brasília, 1994. 